\title{
Without Emotions, Never a Partnership!
}

Tara Hermsen, Department of Learning and Development in Organisations, HAN University of Applied Sciences, Nijmegen, the Netherlands

Thomas Kuiper, Department of Applied Psychology, HAN University of Applied Sciences, Nijmegen, the Netherlands

*Frits Roelofs, Faculty of Health and Social studies, HAN University of Applied Sciences, Nijmegen, the Netherlands

Joost van Wijchen, Department of Physiotherapy, HAN University of Applied Sciences, Nijmegen, the Netherlands

\section{Contact: frits.roelofs@han.nl}

\section{INTRODUCTION}

Tara Hermsen: Many students, including me, don't feel valued during their study. Especially when the teachers' beliefs are along the lines of: "you (student) know nothing yet, though when you stay obedient, we (teachers) will pass our knowledge on to you in the upcoming years." In my opinion, this is still a strong and persistent belief. When I regard a relationship, any relationship, the emotion of being valued can bring so much motivation and joy. The feeling of being appreciated during my study created a world of difference to me. We are equals, even though we differ in age, function, and experience. I am just as valuable as you and we appreciate each other's contributions. We are doing this together even though we both have a different role and task. We are complementary. The moment you experience this complementarity as a student, you and your teacher really engage in a partnership. To achieve this, real contact is crucial. During my study, it was my privilege to experience this several times. Learning and studying are so much more interesting and joyful when this occurs.

This kind of experience is something we wish we could share with every student and teacher. In this opinion piece, we aim to show what is necessary to realise this kind of partnership. We argue that "contact before contract" is the essential foundation, followed by an awareness of complementarity and its importance. We include personal reflections to share the emotions we each have experienced in this process of contact, contract, and complementarity. 
Contact before contract aligns with Stevens' (2002) statement that there is "no performance without relation" (p. 15). The key component to reach success in education is the student-teacher relationship. Before we can start our work (i.e., contract), we first must know-and more importantly feel-who the other is (i.e., contact) and who we are at that moment ourselves.

Emotions are energy. Energy allows us to act (Spanninks, 2011). We often act, however, without getting closer to the desired outcome. We immediately notice it in our own emotions: They turn inwards and become energy consuming and we get frustrated. Our own emotions can, at times, seem synchronised with those of others. Unfortunately, daily practice often shows a different experience within the realms of education. Even so, not only does a strong, mutual partnership among student(s) and teacher(s) help those directly involved, it also brings us closer to the societal aim of education.

\section{CONTACT}

Good contact starts with openness: It is new and exciting; it is unprejudiced, sincere curiosity. What will it look like when students enter the classroom, excited and unprejudiced concerning teachers and their new education? What will it look like when teachers engage students in the same way? According to den Boer (2011), contact means truly understanding what goes on in the other's mind. Truly listening is about understanding not what the other is saying, but what the other wishes to say. It is this kind of contact that leads to a contract (den Boer, 2011).

\section{CONTRACT}

Contact constitutes the foundation of the contract (van der Pol, 2013). Educational contracts exist to establish agreements, eliminating the need to repeatedly settle the same matters. In addition, many agreements also exist in implicit form. For example, teachers should inspire students at the start of the educational journey. Traditionally, teachers know "it" and students don't know "it" yet. But isn't education also, perhaps even primarily, meant to bring new forms of "it" to life? What if students take the initiative? What if "it," as the mutual project of students and teachers, is at the core of education?

\section{ICEBERG}

Tara Hermsen: One of my partnerships happens to be with my thesis supervisor. I would like to show the two stages of our partnership. To visualise my behaviour, beliefs, incentives, and emotions, I have placed them in McClelland's (1989) Iceberg. Iceberg A symbolises the start of our partnership, whereas Iceberg B symbolises the present (a year after Iceberg A). To evolve from A to B the idea of contact before contract was of the utmost importance. It helped me reach a point where I could feel important and valued beyond my research and its results. For me to form a partnership, it must grow and will always keep growing, with ups and downs. We did not go from iceberg A to B in a matter of weeks. In such processes, you don't have to open yourself immediately. In my experience, what works best is to start above the water. With time, you'll slowly reach deeper into the iceberg if both partners are truly committed to and intent on building the partnership. Granting each other time and using emotions are the most important aspects in building and enhancing partnerships. 
Figure 1. Iceberg initial situation

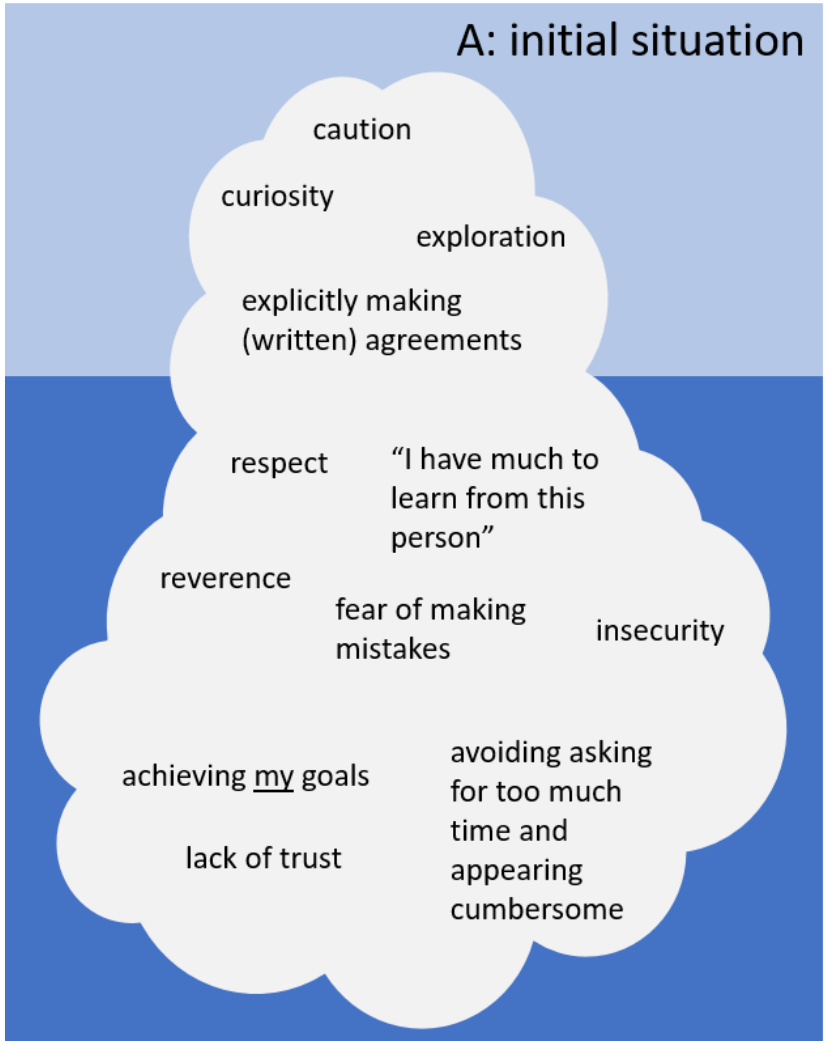

Figure 2. Iceberg partnership

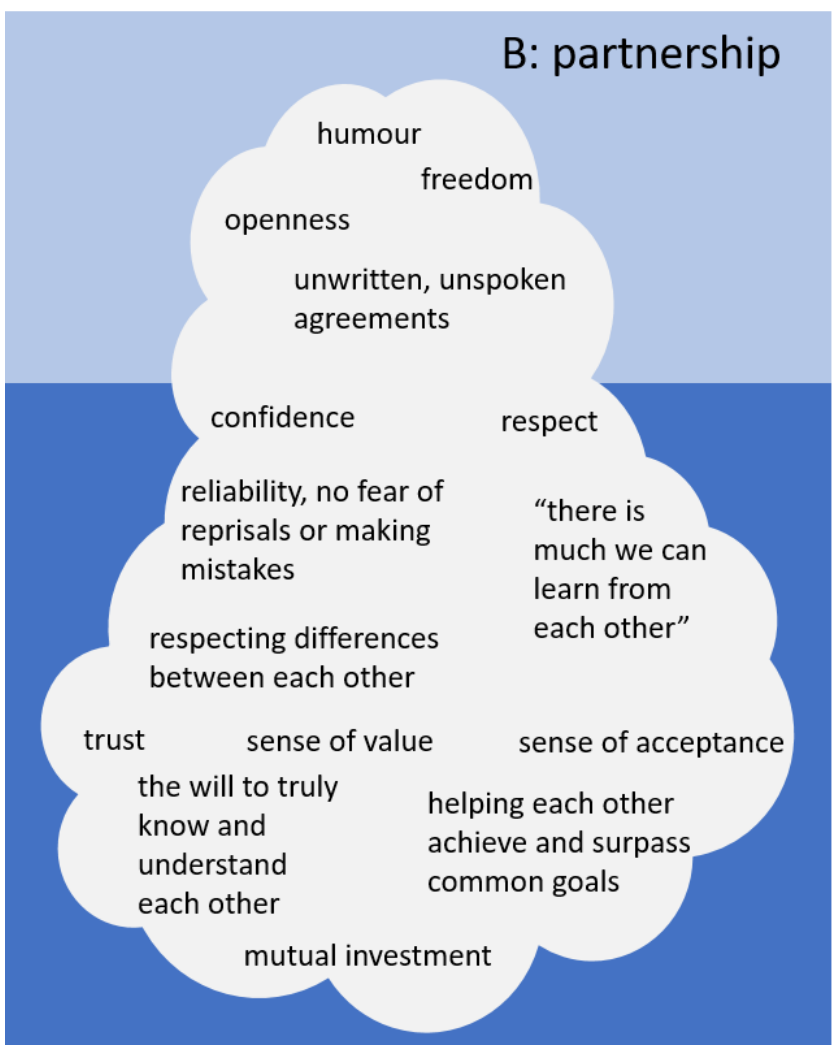

Thomas Kuiper: Judgments are often very strong and as such have great impact. I have the tendency to consider a mark or feedback to be a judgment on myself. Failing a test means I am a failure. For me, the beauty of a non-judgmental attitude lies in the experience that something is neither wrong nor right. This always leads to a dialogue within a partnership. The mark, grade, or judgment is no longer all-decisive in my sense of self-worth. Being non-judgmental towards myself means allowing myself to be me, perceiving tremendous space around me with hardly any constraints. Something which I create is credited by its own merit. It provides me with the stimulus to proceed and the willingness to do and learn even more. For me, real contact is essential for being non-judgmental towards my partner and myself.

\section{COMPLEMENTARITY}

Within every partnership there always exists a mutually experienced, felt, and perceivable notion that exists beyond the level of each individual partner. We all know these kinds of partnerships. The most important is of course our life-partner, though other forms are of interest in this sense: dance-partner, sparring-partner, partner-in-crime, or businesspartner. The term "Students as Partners" might not be the best appellation, as it denotes a relationship perceived from a specific side-the teacher. In our opinion, mutuality, reciprocity, and complementarity are of key importance in the relationship between student and teacher.

It is remarkable, maybe even bizarre, that we had to wait so long before noticing that students and teachers could and should be each other's natural allies, especially within higher education. After all, students and teachers have been within the same educational 
situation for centuries. All around the globe, students and teachers have one huge social mission, or assignment: to provide great learning that eventually will help service society.

A person can only be him- or herself by the grace of the other. One can only be a teacher when others are willing to take the role of students. One can only be a student when collaborating with others, with teachers. Imagine what will happen when this total interdependence is accepted, recognised, and used within higher education by each participant?

In this interdependence, we complement each other-or at least we could, and perhaps should. If, once we have truly made contact, we seek out those areas in which we complement each other, education could attain a goal much more important than it has had thus far. The partner with whom we conduct our greatest human mission, the raising and upbringing of our children, is often also the one who complements us in many ways. In the second greatest human mission - the teaching, guiding, and supporting of all children-so much more can be achieved when both student and teacher are aware of the potential of partnership.

\section{OUR FINAL REFLECTIONS}

So, make contact before contract. In every partnership complementarity is different because the people and the emotions are different. Be aware of the essential nature of complementarity in your partnerships. Be careful and gentle with your own emotions and the emotions of others. Learn to notice, accept, interpret, understand, use, and apply them, without getting entangled in judgments. Take your time and stay away from prejudices. It's hard work, but it will melt icebergs.

Undoubtedly you, as a reader, experienced something while reading the above. Would you be so kind to share with us the emotions you experienced while reading this opinion piece? What interpretations or confusion did it create? What do these emotions mean to you, to us, to education?

\section{NOTES}

1. This opinion piece was a collaboration of four very different people (see our biographies, below). The outcomes of our brainstorm sessions and deep conversations are translated in the text above. This opinion piece is extraordinary because, despite our differences and different backgrounds, we all identify with each other's contributions. It was a true partnership.

\section{NOTE ON CONTRIBUTORS}

Tara Hermsen is an undergraduate student of Learning and Development in Organizations at the HAN University of Applied Sciences. During the writing of this article she writes her thesis about the behavior of teachers in partnerships. She researches which teacher behavior is required in a partnership and advises learning interventions to develop this behavior.

Thomas Kuiper is currently an undergraduate student of Applied Psychology at the HAN University of Applied Sciences. His affection for Students as Partners began to develop during his internship at the Faculty of Health and Behavioral Sciences. Analyzing change in behavior of students is what he likes most. 
Frits Roelofs is policy advisor of the HAN University of Applied Sciences of Arnhem and Nijmegen. The first 30 years of his career he worked as teacher and developer of Dutch Language and Literature in Secondary Schools, the last 10 years as advisor in Higher Education. His specialties are: Students as Partners and the connection between Secondary and Higher Education.

Joost van Wijchen is a physiotherapist, a senior lecturer and educational designer of physiotherapy and health studies at the HAN University of Applied sciences. To his opinion, in both health and education, collaboration, adaptability and solvability are the basic elements. He believes in learning as a connectivistic process among participants and as such in partnership among students and teachers.

\section{REFERENCES}

Spaninks, J.-L. (2011). Emotioneel meesterschap: Leer negatieve gevoelens omzetten naar positieve emoties. Houten-Antwerpen: Uitgeverij Unieboek.

Stevens, L. (2002). Zin in leren. Apeldoorn: Maklu en Garant Uitgevers.

Den Boer, B. (2011). Echt contact: Hoe zorg je ervoor dat het klikt? Schiedam: Scriptum Psychologie.

Van der Pol, I. G. M. (2013). Coachen als professie: Fundamenten voor begeleiding naar heelheid (2e druk). Amsterdam: Uitgeverij Boom/Nelissen. 